\title{
EFFECTIVENESS OF ACUPUNCTURE AND INFRARED THERAPIES FOR REDUCING MUSCULOSKELETAL PAIN IN THE ELDERLY
}

\author{
Risna Widowati ${ }^{1)}$, Bhisma Murti²), Eti Poncorini Pamungkasari3) \\ 1)Acupuncture Unit, School of Health Polytechnics, \\ Ministry of Health, Surakarta \\ 2)Masters Program in Public Health, Sebelas Maret University \\ 3)Department of Public Health, Faculty of Medicine, Sebelas Maret University
}

\begin{abstract}
Background: According to the World Health Organization, the most frequent health problems experienced by the elderly is musculoskeletal pain. The common treatment for musculoskeletal pain is Non-Steroidal AntiInflammatory Drugs (NSAID) drugs. These drugs, however, give undesireable side effects such as disorders in digestion, renal function, and increased blood pressure. Acupuncture and infrared therapies have been widely known as cheap and safe for musculoskeletal pain. However, their relative effectiveness are not yet clear. This study aimed to determine the effectiveness of acupuncture and infrared therapies for reducing musculoskeletal pain in the elderly.
\end{abstract}

Subjects and Method: This was an experiment study with randomized controlled trials design. The study was conducted at the elderly integrated health post Klodran, Karanganyar, Central Java, in May, 2016. A total sample of 60 elderlies was selected for this study using random sampling technique. This sample was randomized into 4 groups, each consisting of 15 study subjects: (1) acupressure; (2) acupuncture; (3) infrared; (4) acupuncture and infrared. The dependent variable was musculoskeletal pain. The independent variable was type of pain relief therapy. The data was analyzed by Kruskall Wallis Test, and post-hoc test using Mann-Whitney.

Results: Kruskall Wallis Test showed mean differences in the reduction of musculosceletal pain between the four groups, and they were statistically significant, as follows: acupressure (mean=1.3; $\mathrm{SD}=0.5)$, acupunture (mean= 2.3; $\mathrm{SD}=0.5$ ), infrared (mean=1.6; $\mathrm{SD}=0.6)$, and acupuncture and infrared (mean= $3.9 ; \mathrm{SD}=0.4)$. Mann-Whitney test showed the most effective treatment for reducing musculoskeletal pain was acupunture and infrared combination therapy (mean difference $=2.53 ; \mathrm{p}<0.001$ ).

Conclusion: Acupunture and infrared combination is the most effective treatment for reducing musculoskeletal pain in the elderly.

Keywords: musculoskeletal pain, acupressure, acupuncture, infrared, elderly

Correspondence: Risna Widowati. Acupuncture Unit, School of Health Polytechnics, Ministry of Health, Surakarta, Central Java. Email: risna.widowati@gmail.com. Mobile: +6281555742729. 